\title{
Circadian variation in abomasal digesta flow in grazing ewes during lactation
}

\author{
BY H. DOVE \\ CSIRO Division of Plant Industry, GPO Box 1600, Canberra, ACT 2601, Australia \\ AND J. A. MILNE, A. M. SIBBALD, C. S. LAMB AND H. A. MCCORMACK \\ Macaulay Land Use Research Institute, Bush Estate, Penicuik, Midlothian EH26 OPY
}

(Received 8 February 1988 - Accepted 21 July 1988)

\begin{abstract}
1. Lactating grazing ewes, fistulated at the rumen and abomasum were either not supplemented or offered, individually, $600 \mathrm{~g} / \mathrm{d}$ of either pelleted, molassed sugar-beet pulp ('energy' supplement) or a pelleted $1: 1(\mathrm{w} / \mathrm{w}$ ) mixture of this feed and formaldehyde-treated soya-bean meal ('protein' supplement). Digesta flows at the abomasum were estimated from the concentrations of the markers CrEDTA and ruthenium phenanthroline complex, during their administration by continuous intra-rumen infusion. Digesta samples were taken at 09.00 hours and at six further times at $4 \mathrm{~h}$ intervals. This was repeated $2 \mathrm{~d}$ later.

2. No significant difference in flow between days was noted. Daily flows of dry matter (DM) and non-ammonianitrogen (NAN) (g/d) in supplemented ewes were significantly higher than in unsupplemented ewes, both in total digesta and its particulate phase. However, there were significant differences between sampling times or significant interactions between sampling time and supplement treatment. The results were therefore examined by Fourier analysis for possible circadian variation in digesta flow. As there was marked between-animal variability in flowrate, the digesta-flow values for each sampling time were re-expressed as percentages of the flows calculated from daily mean marker concentrations.

3. In unsupplemented animals, marked and significant circadian variation was then identified in the flow of DM, total $N$ and NAN in both whole digesta and the particulate phase. There was also significant circadian variation in the flow of DM, total N and NAN in the digesta of the supplemented ewes. Curves were of the same general shape as those for unsupplemented animals, but some significant differences were found, principally for digesta NAN flow. In both supplemented and unsupplemented animals, peak flows occurred in the period $20.00-01.00$ hours. The proportion of DM and NAN flowing in the particulate phase was relatively constant through the day for unsupplemented ewes, but significant circadian variation occurred for supplemented ewes.

4. The possible mechanisms generating the circadian variation in digesta flow, such as grazing behaviour and the rumen digestion of supplements, are discussed. Values are also presented to indicate the extent of the likely errors if digesta flows were estimated from samples which did not represent all stages of the circadian pattern.
\end{abstract}

Studies of supplementary feeding in grazing, lactating ewes have frequently found that the response to supplements is variable (e.g. Milne et al. 1981; Dove et al. 1984a,b). This is partly related to between-animal variability in supplement intake (Dove, 1984; Dove et al. $1984 b$ ) but, even at constant intake, variability in response may also be related to individual differences in the effect of supplements on the kinetics of digestion. These effects are not yet understood. They are also difficult to measure, because the pools and flows of digesta, particulary in grazing sheep, are not constant, but exhibit marked circadian variation (Corbett \& Pickering, 1983; Thomson et al. 1985). Hence, in studies of digesta flow in the field, it would be possible to obtain biassed estimates of the flow of digesta through the choice of inappropriate sampling times.

Within the context of a larger study of the response of the lactating, grazing ewe to supplements, we investigated: (a) the extent of circadian variation in digesta flow, (b) the effect, on any circadian variation, of feeding supplements designed to increase the supply of metabolizable energy or protein, and (c) the effect of possible circadian variation on the errors of estimating abomasal digesta flow from samples taken at intervals during the day. 
A brief report concerning abomasal digesta flows up to week 8 of lactation has appeared previously (Dove et al. 1985).

\section{MATERIALS AND METHODS \\ Experimental design}

The results reported here were obtained as part of a larger experiment consisting of four replicates (fields) on which four treatments were randomly allocated, i.e. two unsupplemented treatments (high herbage mass, low herbage mass), one treatment on which ewes received an 'energy' supplement and one treatment on which ewes received a 'protein' supplement (for details of supplements, see below). The present results were obtained in one of these replicates, in which surgically prepared ewes grazed together with the unfistulated animals (with appropriate increases in plot size). However, by the start of the present measurements, rapid pasture growth had resulted in similar herbage mass of about 2000 $\mathrm{kg}$ organic matter $(\mathrm{OM}) / \mathrm{ha}$ on all four plots in this replicate, so that no differences between the two unsupplemented plots were detected. For the remainder of the present paper, values from these two groups have been pooled, so that there are, effectively, three treatments.

In assessing the treatment differences discussed later (p. 656), it should be noted that, in working within one replicate, between-treatment differences were confounded with possible between-plot differences. However, the evenness of the herbage masses between plots, the marked similarity of responses on the two unsupplemented plots and the marked similarity of all responses to previous work suggest that this confounding was not a problem.

\section{Pastures and supplements}

The four treatments were imposed on four 0.62 ha plots of perennial ryegrass (Lolium perenne L.) pasture which had received $40 \mathrm{~kg} \mathrm{~N} / \mathrm{ha}$ as a compound fertilizer (N-phosphorus-potassium in the proportions $22: 11: 11$ by wt) $30 \mathrm{~d}$ and again $10 \mathrm{~d}$ before the start of the present measurements. Herbage mass was determined in each plot immediately before and after the measurement period by cutting nine quadrats $(155 \times 1200 \mathrm{~mm})$ to ground level. Samples so collected were dried at $100^{\circ}$ and ashed overnight at $450^{\circ}$ to determine OM content.

The 'energy' supplement was commercial pelleted molassed-sugar-beet pulp (OM 926, $\mathrm{N} 19.0 \mathrm{~g} / \mathrm{kg}$ dry matter (DM)) offered to each sheep at the rate of $600 \mathrm{~g} / \mathrm{d}$ (air dry). The 'protein' supplement consisted of a $1: 1(\mathrm{w} / \mathrm{w})$ mixture of the sugar-beet pulp plus formaldehyde-treated soya-bean meal. Formaldehyde treatment was carried out as described by Freer \& Dove (1984) and, following $7 \mathrm{~d}$ of curing, treated meal was mixed with hammer-milled sugar-beet pulp and re-pelleted. This supplement (OM 923, N $49.8 \mathrm{~g} / \mathrm{kg}$ DM) was also offered to each sheep at $600 \mathrm{~g} / \mathrm{d}$ (air dry).

\section{Animals and their management}

Each experimental plot was grazed by nine lactating Border Leicester $\times$ Scottish Blackface ewes (and their lambs), three of which were fistulated at the rumen and abomasum. Performance findings from the unfistulated ewes will be reported elsewhere. Digesta flow values were obtained from only eleven of the twelve fistulated ewes and, of these, six ewes suckled single lambs and five suckled twins. Values from single- and twin-suckling ewes were pooled within treatment since no significant differences between them were detected. At the start of measurements, the fistulated ewes were at day 85 (SD 9.8) of lactation.

Supplemented animals were collected daily from the field and offered supplements, individually, between 08.00 and 09.00 hours GMT. The entire procedure of collection, feeding and return of animals usually took less than 20 min for each group. 


\section{Measurement of digesta flow}

The flow of abomasal digesta was estimated from the dilution of the particulate phase marker Tris-(1,10-phenanthroline)-ruthenium (II) chloride and the liquid-phase marker CrEDTA, prepared by the methods of Tan et al. (1971) and Binnerts et al. (1968) respectively, and administered by continuous intra-rumen infusion.

On the 1st day of infusion, all fistulated ewes were given a priming dose via the rumen cannula of $100 \mathrm{ml}$ of a solution containing $355 \mathrm{mg}$ ruthenium $/ \mathrm{kg}$ and $1050 \mathrm{mg}$ chromium/ $\mathrm{kg}$. Thereafter, the infusate was administered directly to the rumen at the continuous rate of about $3 \mathrm{ml} / \mathrm{h}$ by peristaltic pumps carried by the animals. The pumps were similar in operation to those of Corbett et al. (1976). Four $1.5 \mathrm{~V}$ dry batteries powered an Escap 28 DC motor which, through an Escap A42 gearbox (reduction 2160:1; Portescap UK Ltd, Reading) turned a $30 \mathrm{~mm}$ diameter PTFE rotor at $1.2 \mathrm{rev} . / \mathrm{min}$. Infusates were delivered through silicon tubing stretched around the rotors. The mean coefficient of variation of delivery rate was $2.5(\mathrm{SD} 1 \cdot 77) \%$. The actual amounts infused were determined from the loss of weight of the infusion packs, which were changed daily.

On day 6 of infusion, samples of approximately $20 \mathrm{ml}$ rumen fluid and $100 \mathrm{ml}$ abomasal digesta were obtained at about 09.00 hours, immediately before the feeding of supplements to the animals. Samples were then taken every $4 \mathrm{~h}$, up to and including 09.00 hours on day 7. This procedure was repeated starting on day 8 of infusion so that samples were obtained at each of seven times on each of $2 \mathrm{~d}$. For each group of ewes, the sampling procedure usually occupied about $15 \mathrm{~min}$ and grazing usually continued when the animals were returned to the field.

\section{Processing of samples and chemical analyses}

Samples of rumen fluid for the determination of rumen ammonia were acidified immediately with 1-2 drops of concentrated sulphuric acid. Abomasal digesta samples collected during daylight hours were chilled immediately and processed that evening. Samples collected overnight were chilled and processed the next day with the last samples, collected at 09.00 hours. A subsample of $50 \mathrm{~g}$ was removed ('digesta' sample). The remainder was then centrifuged at $1200 \mathrm{~g}$ for $15 \mathrm{~min}$ and the sediment collected as the 'particulate' fraction. After separation, fractions were freeze-dried.

The OM contents of the supplements were determined by drying at $80^{\circ}$ for $24 \mathrm{~h}$ followed by ashing overnight at $450^{\circ}$. OM digestibilities of supplements and of pasture samples, collected using oesophageally fistulated sheep, were determined in vitro by the method of Tilley \& Terry (1963) as modified by Alexander \& McGowan (1966). The rate of rumen degradation of DM and $\mathrm{N}$ in the supplements was estimated from samples incubated in nylon bags in the rumen of sheep similar to the grazing fistulates, using the procedures and methods described by Freer \& Dove (1984).

$\mathrm{NH}_{3}$ concentrations in rumen fluid and abomasal samples were determined by steam distillation. $\mathrm{N}$ contents were determined by semi-microKjeldahl procedure. The concentrations of $\mathrm{Ru}$ and $\mathrm{Cr}$ in the infusate, digesta and faeces samples were determined by $\mathrm{X}$-ray fluorescence spectrometry (Evans et al. 1977). However, some samples proved to have very low $\mathrm{Cr}$ levels. These were re-analysed by atomic absorption spectrometry using an Instrumentation Laboratory Video 22 spectrometer operating with a nitrous oxide-acetylene flame.

\section{Calculation of digesta flows}

The concentrations of $\mathrm{Cr}$ and $\mathrm{Ru}$ in the digesta and particulate phases were used to compute apparent flows of abomasal digesta $(\mathrm{g} / \mathrm{d})$ at each time of sampling, using the 
'double-marker' procedures described by Faichney $(1975 a, 1980)$. The mean daily flow of digesta was similarly estimated from the mean of the $\mathrm{Ru}$ and $\mathrm{Cr}$ concentrations in the separate samples collected on that day. As Faichney (1980) discussed, the double-marker procedures should, strictly, only be applied where steady-state conditions are known to exist. With non-steady state, the two digesta markers should be used independently (Faichney, 1980), though this involves the assumption of ideal marker behaviour. However, the results presented by Faichney (1980) also indicate that, even with a single, large meal per day, the differences in flow estimated by using the double-marker rather than the independent, two-marker procedure were 'so small as to be of no practical significance' (Faichney, 1980). Since our ewes grazed for extended periods, the error associated with our use of the double-marker procedure is likely to be even smaller.

In addition to the previously described calculations, an assessment of the flow of the particulate phase of digesta was obtained by using the $\mathrm{Ru}$ concentrations in samples of that phase, with the assumption that $\mathrm{Ru}$ was behaving as an ideal marker of that phase.

\section{Statistical analyses}

Initially, all results were examined by analysis of variance, investigating the effects of sampling day, sampling time within sampling day, supplementation treatment and variation between animals. Significant between-sheep differences were detected in the absolute levels of digesta flow, so to facilitate comparisons, the seven estimates of apparent flow for each animal on each day were expressed as a percentage of the flow calculated from mean marker concentrations. The values so expressed were re-examined by analysis of variance within each treatment, assessing the separate effects of sheep, day, sampling time and their interactions. The effect of sampling time was further subdivided into four Fourier terms ( $\sin (t), \cos (t), \sin (2 t), \cos (2 t)$ with time $t$ expressed in hours) to examine the circadian pattern of digesta flows. These Fourier terms were not tested against the total error mean square, but against individual Fourier components of the error term, derived using the procedures of Rowell \& Walters (1976) for the analysis of contrasts over time. No between-sheep or between-day differences were detected in the analyses of variance and interactions were rarely significant, but there were significant effects of sampling time. In subsequent analyses, results for the $2 \mathrm{~d}$ for each sheep were combined. Similarly, no differences were detected between the responses on the two unsupplemented plots and, in the remainder of the present paper, values from these groups have been pooled.

The possibility of circadian variation in digesta flow was then examined by Fourier analysis based on individual data points, using the OPTIMIZE routine in GENSTAT (1977). The model used was similar to that described by Corbett \& Pickering (1983), i.e.

$$
Y=a+b \sin (t)+c \cos (t)+d \sin (2 t)+e \cos (2 t)
$$

where $Y$ is apparent digesta flow in an animal, expressed in either absolute or percentage terms and $t$ is the time expressed in hours converted to radians by multiplying by $2 \pi /$ $24(=0.2618)$, since preliminary analyses had indicated that the fundamental period of the fitted Fourier relations did not differ significantly from $24 \mathrm{~h}$.

The significance of the fitted Fourier relations, that is, the extent to which the pattern of digesta flow departed in cyclical fashion from the value calculated from mean marker concentrations, was assessed from the comparison of the mean squares for regression and for residuals. The significance of differences between fitted curves (e.g. between different supplement treatments) was assessed from the reduction in the residual mean square effected by fitting separate curves through the values, rather than a common curve. The significance of differences in the pattern of flow of components (i.e. DM, non- $\mathrm{NH}_{3}-\mathrm{N}$ (NAN)) within a phase (digesta, particulate phase) of a given treatment was examined by 
calculating the arithmetic differences (at a given time) between the components in a phase (or the same component in different phases) and testing as described previously for circadian variation in the pattern of the differences.

\section{RESULTS \\ Pastures and supplements}

Pasture availability in the unsupplemented plots was 1998 (SE 155.9) $\mathrm{kg} \mathrm{OM} / \mathrm{ha}$, and in the plots where ewes received energy or protein supplements was 1958 (SE 133.4) and 2275 (SE $155.8) \mathrm{kg} \mathrm{OM} /$ ha respectively. These levels of herbage mass would be unlikely to limit herbage intake in lactating ewes (Milne et al. 1981). The in vitro digestibility of OM in the oesophageal extrusa samples collected from the plots was 0.76 (SE 0.004), with no difference between plots.

Faecal outputs were estimated from the Ru concentration in bulked faecal grab samples collected over the digesta sampling period. After adjustment for faeces arising from the supplement, pasture OM intakes in the unsupplemented and supplemented groups were 1505 (SE $164 \cdot 2$ ) and 1515 (SE $258 \cdot 8$ ) g/d respectively.

The energy supplement had an OM digestibility in vitro of 0.90 and $83.1 \%$ of the DM of this supplement disappeared after $24 \mathrm{~h}$ of incubation in nylon bags in the rumen. The equivalent disappearance of DM in the treated soya-bean was $43.8 \%$ but the disappearance from a $1: 1(\mathrm{w} / \mathrm{w})$ pelleted mixture of the treated soya-bean meal and the sugar-beet pulp was $69.7 \%$, which is $6.2 \%$ higher than the arithmetic average of the above figures. This apparent effect of pelleting on disappearance rate of formaldehyde-treated material has been observed previously (Freer \& Dove, 1984).

Though formaldehyde treatment clearly decreased rumen degradation of the soya-bean meal and thus of the protein supplement, the in vitro digestibility $(0.90)$ was the same as that of the energy supplement.

Ewes given the energy supplement consumed 506 (SE 9.4) $\mathrm{g} \mathrm{OM} / \mathrm{d}$ as supplement, while those given the protein supplement ate only 318 (SE 66.8) g OM/d as a supplement. This was in contrast to earlier periods in lactation in the same animals (Dove et al. 1985), in which supplement intakes were much the same.

\section{$\mathrm{NH}_{3}$ concentrations and absolute flows of DM and $\mathrm{NAN}$}

$\mathrm{NH}_{3}$ concentrations in the rumen and in abomasal digesta were similar to those recorded earlier in lactation (Dove et al. 1985). The effect of supplement treatment was not significant and Fourier analysis failed to identify any significant circadian variation.

Abomasal DM flows averaged $995 \mathrm{~g} / \mathrm{d}$ in unsupplemented ewes and $1294 \mathrm{~g} / \mathrm{d}$ in supplemented ewes, while the corresponding flows of NAN were 42 and $65 \mathrm{~g} / \mathrm{d}$ respectively. These are consistent with the flows reported for earlier stages of lactation (Dove et al. 1985). However, there was highly significant between-sheep variability in digesta flow $(P<0.001)$, presumably because of between-sheep variability in intake. When flow-rate values were reexpressed as percentages of flows calculated from mean marker concentrations, these between-sheep differences were reduced to non-significant levels. However, there were still significant treatment effects for digesta DM flow $(P<0.05)$ and NAN flow $(P<0.025)$ and significant differences between sampling times for the flow of DM $(P<0.025)$ and NAN $(P<0.025)$ in the particulate phase.

\section{Circadian variation in digesta flow}

The circadian variation in digesta flow became more evident after re-expression of flows as percentages of the daily flow calculated from mean marker concentrations. Coefficients of 
Table 1. Coefficients of the Fourier equations describing circadian variation in the estimated flows of dry matter $(D M)$, total nitrogen and non-ammonia- $N(N A N)$ in the abomasal contents of unsupplemented ewes grazing perennial ryegrass (Lolium perenne $L$.)

(Flow estimated at time $t$ (radians, GMT) as a percentage of daily flow estimated from $24 \mathrm{~h}$ mean marker concentrations, where flow $=a+b \sin (t)+c \cos (t)+d \sin (2 t)+e \cos (2 t))$

\begin{tabular}{|c|c|c|c|c|c|c|c|c|}
\hline \multirow[b]{2}{*}{ Phase } & \multirow[b]{2}{*}{ Component } & \multicolumn{5}{|c|}{ Regression coefficients } & \multirow{2}{*}{$\begin{array}{c}\text { Residual } \\
\text { SD }\end{array}$} & \multirow{2}{*}{$\begin{array}{c}\text { Statistical } \\
\text { significance: } \\
P<\end{array}$} \\
\hline & & $a$ & $b$ & $c$ & $d$ & $e$ & & \\
\hline Digesta & $\begin{array}{l}\text { DM } \\
N \\
\text { NAN }\end{array}$ & $\begin{array}{l}105 \cdot 41 \\
103 \cdot 64 \\
103 \cdot 02\end{array}$ & $\begin{array}{l}1 \cdot 48 \\
3 \cdot 31 \\
4.59\end{array}$ & $\begin{array}{l}17 \cdot 54 \\
19 \cdot 51 \\
18 \cdot 12\end{array}$ & $\begin{array}{l}3.64 \\
1.62 \\
3.29\end{array}$ & $\begin{array}{l}3 \cdot 08 \\
8 \cdot 86 \\
7 \cdot 58\end{array}$ & $\begin{array}{l}22 \cdot 079 \\
26 \cdot 721 \\
27 \cdot 126\end{array}$ & $\begin{array}{l}0.01 \\
0.025 \\
0.025\end{array}$ \\
\hline Particulate & $\begin{array}{l}\text { DM } \\
\text { N } \\
\text { NAN }\end{array}$ & $\begin{array}{l}109 \cdot 50 \\
110 \cdot 86 \\
109 \cdot 82\end{array}$ & $\begin{array}{l}-4 \cdot 90 \\
-7 \cdot 61 \\
-7 \cdot 28\end{array}$ & $\begin{array}{l}26 \cdot 95 \\
28 \cdot 73 \\
28 \cdot 09\end{array}$ & $\begin{array}{l}-5 \cdot 96 \\
-8 \cdot 49 \\
-8 \cdot 99\end{array}$ & $\begin{array}{l}7.69 \\
6.60 \\
5.90\end{array}$ & $\begin{array}{l}25 \cdot 109 \\
30 \cdot 383 \\
29 \cdot 413\end{array}$ & $\begin{array}{l}0.001 \\
0.001 \\
0.001\end{array}$ \\
\hline
\end{tabular}

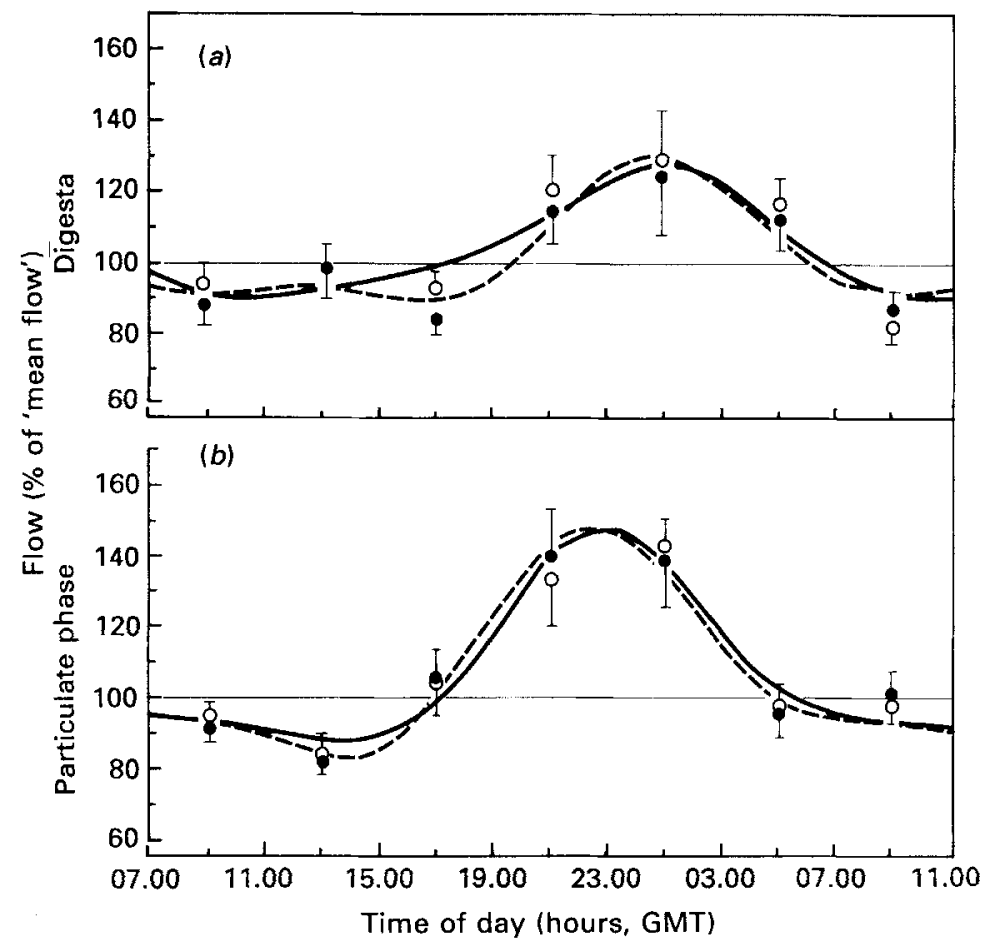

Fig. 1. Circadian variation in the flows of dry matter $(\mathrm{O}-\mathrm{O})$ and non-ammonia-nitrogen $(0 \ldots)$ in (a) whole digesta and $(b)$ the particulate phase of digesta in unsupplemented ewes, grazing perennial ryegrass (Lolium perenne L.), expressed in relation to the flow calculated from mean marker concentrations. Points represent means with their standard errors represented by vertical bars, across sheep and sampling days. The equations for the fitted Fourier curves are given in Table 1 . 
Table 2. Coefficients of the Fourier equations describing circadian variation in the estimated flows of dry matter (DM), total nitrogen and non-ammonia-N $(N A N)$ in the abomasal contents of supplemented ewes grazing perennial ryegrass (Lolium perenne $L$.)

(Flow estimated at time $t$ (radians, GMT) as a percentage of daily flow estimated from $24 \mathrm{~h}$ mean marker concentrations, where flow $=a+b \sin (t)+c \cos (t)+d \sin (2 t+e \cos (2 t))$

\begin{tabular}{|c|c|c|c|c|c|c|c|c|}
\hline \multirow[b]{2}{*}{ Supplement } & \multirow{2}{*}{$\begin{array}{l}\text { Phase } \\
\text { component }\end{array}$} & \multicolumn{5}{|c|}{ Regression coefficients } & \multirow{2}{*}{$\begin{array}{l}\text { Residual } \\
\text { SD }\end{array}$} & \multirow{2}{*}{$\begin{array}{c}\text { Statistical } \\
\text { significance : } \\
P<\end{array}$} \\
\hline & & $a$ & $b$ & $c$ & $d$ & $e$ & & \\
\hline \multirow[t]{2}{*}{ Energy } & $\begin{array}{l}\text { Digesta } \\
\text { DM } \\
\text { N } \\
\text { NAN }\end{array}$ & $\begin{array}{l}115 \cdot 23 \\
118 \cdot 77 \\
113 \cdot 79\end{array}$ & $\begin{array}{l}-16 \cdot 76 \\
-20 \cdot 18 \\
-17 \cdot 30\end{array}$ & $\begin{array}{l}22 \cdot 89 \\
29 \cdot 90 \\
25 \cdot 44\end{array}$ & $\begin{array}{l}-4 \cdot 7 \\
-\cdot \cdot 38 \\
-9 \cdot 24\end{array}$ & $\begin{array}{l}20 \cdot 61 \\
19 \cdot 90 \\
16.95\end{array}$ & $\begin{array}{l}32 \cdot 670 \\
30 \cdot 950 \\
27 \cdot 659\end{array}$ & $\begin{array}{l}0.05 \\
0.005 \\
0.01\end{array}$ \\
\hline & $\begin{array}{l}\text { Particulate } \\
\text { DM } \\
\text { N } \\
\text { NAN }\end{array}$ & $\begin{array}{l}106 \cdot 53 \\
110 \cdot 07 \\
108 \cdot 70\end{array}$ & $\begin{array}{l}-2 \cdot 29 \\
-6 \cdot 55 \\
-7 \cdot 17\end{array}$ & $\begin{array}{l}19 \cdot 25 \\
28 \cdot 71 \\
28 \cdot 30\end{array}$ & $\begin{array}{l}-0 \cdot 50 \\
-3 \cdot 00 \\
-3 \cdot 22\end{array}$ & $\begin{array}{l}6 \cdot 26 \\
8 \cdot 55 \\
8 \cdot 23\end{array}$ & $\begin{array}{l}18 \cdot 745 \\
23 \cdot 224 \\
22 \cdot 910\end{array}$ & $\begin{array}{l}0.005 \\
0.001 \\
0.001\end{array}$ \\
\hline \multirow[t]{2}{*}{ Protein } & $\begin{array}{l}\text { Digesta } \\
\text { DM } \\
\text { N } \\
\text { NAN }\end{array}$ & $\begin{array}{l}105 \cdot 42 \\
104 \cdot 38 \\
106 \cdot 50\end{array}$ & $\begin{array}{l}-14 \cdot 85 \\
-18 \cdot 72 \\
-26 \cdot 12\end{array}$ & $\begin{array}{l}12 \cdot 61 \\
18 \cdot 72 \\
16 \cdot 25\end{array}$ & $\begin{array}{l}-5 \cdot 24 \\
-8 \cdot 46 \\
-5 \cdot 58\end{array}$ & $\begin{array}{l}7 \cdot 02 \\
5 \cdot 09 \\
2 \cdot 67\end{array}$ & $\begin{array}{l}25 \cdot 015 \\
23 \cdot 892 \\
28 \cdot 203\end{array}$ & $\begin{array}{c}0.05<P<0.10 \\
0.01 \\
0.025\end{array}$ \\
\hline & $\begin{array}{l}\text { Particulate } \\
\text { DM } \\
\text { N } \\
\text { NAN }\end{array}$ & $\begin{array}{l}103 \cdot 57 \\
103 \cdot 04 \\
104 \cdot 12\end{array}$ & $\begin{array}{l}-3 \cdot 81 \\
-4 \cdot 83 \\
-4 \cdot 75\end{array}$ & $\begin{array}{l}7 \cdot 17 \\
9 \cdot 42 \\
9 \cdot 91\end{array}$ & $\begin{array}{l}-2 \cdot 04 \\
-1 \cdot 34 \\
-1 \cdot 66\end{array}$ & $\begin{array}{r}8 \cdot 12 \\
12 \cdot 24 \\
12 \cdot 41\end{array}$ & $\begin{array}{l}16 \cdot 569 \\
18 \cdot 939 \\
20 \cdot 594\end{array}$ & $\begin{array}{l}\text { NS } \\
\text { NS } \\
\text { NS }\end{array}$ \\
\hline
\end{tabular}

NS, Not significant.

the Fourier equations describing flows so expressed are shown in Table 1 for unsupplemented ewes.

Marked and significant circadian variation was evident in the flows of DM, total $\mathrm{N}$ and NAN in both whole digesta and its particulate phase. The most obvious feature of our curves was a peak flow occurring at approximately $21.00-01.00$ hours. In whole digesta, shown in Fig. 1 (a), the fitted curves for both DM and NAN flows ranged from $15 \%$ below to $30 \%$ above mean daily flow; the patterns of DM or NAN flow did not differ significantly from each other. Similarly, the patterns of DM and NAN flow in the particulate phase did not differ significantly from each other (Fig. $1(b)$ ) and did not differ significantly from their counterparts in whole digesta.

In ewes given the energy supplement, there was significant circadian variation in DM, total $\mathrm{N}$ and NAN flows in both whole digesta and in the particulate phase (Table 2). In ewes given the protein supplement, significant circadian variation was identified for the flows of DM, N and NAN in whole digesta. The Fourier curves fitted to flows in the particulate phase were of the same general shape as the other curves, but did not achieve overall statistical significance. As was the case with unsupplemented animals, the patterns of $\mathrm{DM}$, total $\mathrm{N}$ or NAN flow within a given treatment and phase did not differ significantly from each other.

The curve for digesta DM flow in ewes given the energy supplement (Fig. 2(a)) had a greater amplitude than those in the other treatments, but the general shape of these curves was similar and they were not statistically different. The curves for the two supplemented groups also were not statistically different.

In the case of digesta NAN flow (Fig. 2(b)), the fitted curves for the supplemented groups 


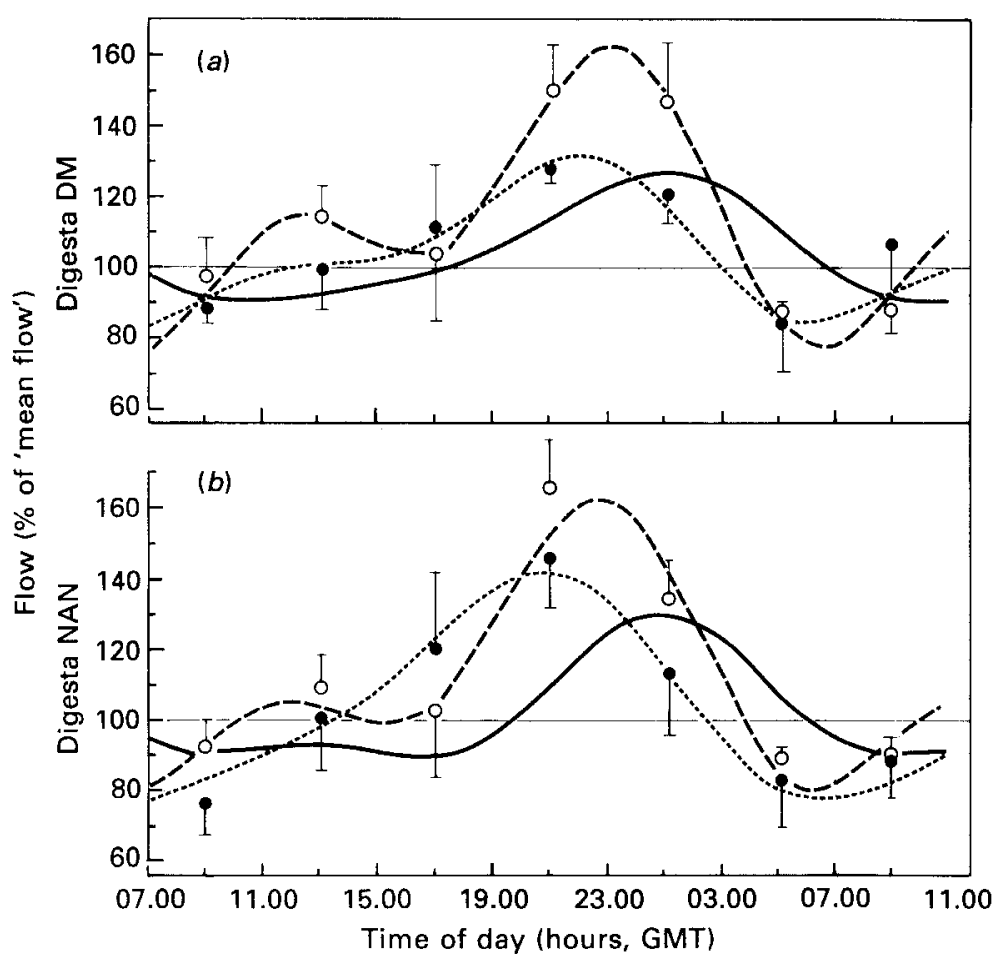

Fig. 2. Circadian variation in the flows of (a) dry matter (DM) and (b) non-ammonia-nitrogen (NAN) in the whole digesta of ewes grazing perennial ryegrass (Lolium perenne L.) and given either the energy supplement (600 g pelleted molassed sugar-beet pulp (MSBP)) $\left(\mathrm{O}_{--} \mathrm{O}\right)$ or protein supplement $(600 \mathrm{~g}$ MSBP-formaldehyde-treated soya-bean meal $(1: 1, w / w))(. . .0)$. Points represent means, with their standards errors represented by vertical bars, across sheep and sampling days. The equations describing the fitted Fourier curves are given in Table 2. Curves for unsupplemented ewes (-) are shown for comparison.

differed significantly from that for unsupplemented animals $(P<0 \cdot 05)$, but not from each other.

The curves for the flow of DM in the particulate phase (Fig. 3(a)) were more similar in shape for the three treatment groups than the curves for whole digesta and were not significantly different. Curves describing the flow of NAN in the particulate pahse did not differ significantly.

To examine whether there was circadian variation in the disposition of flow between the liquid and particulate phases of digesta, Fourier curves were then fitted to values for the calculated proportion of DM or NAN flowing in the particulate phase. These are shown in Table 3 and in Fig, 4 respectively for each of the three treatment groups. In unsupplemented animals, it is clear that the proportion of DM or NAN flowing in the particulate phase was relatively constant throughout the $24 \mathrm{~h}$, at approximately $60 \%$. In the case of DM flow, the fitted curves suggest an increase in proportion of flow in the particulate phase in the period soon after supplementation in ewes given the protein supplement, followed by a return to the same level as the unsupplemented animals. While this is in accord with a possible interpretation of the curves in Figs. 2(a) and 3(a), it should be stressed that the curves in Fig. 4(a) were not significantly different from each other.

However, in the case of the proportion of NAN flowing in the particulate phase, the 


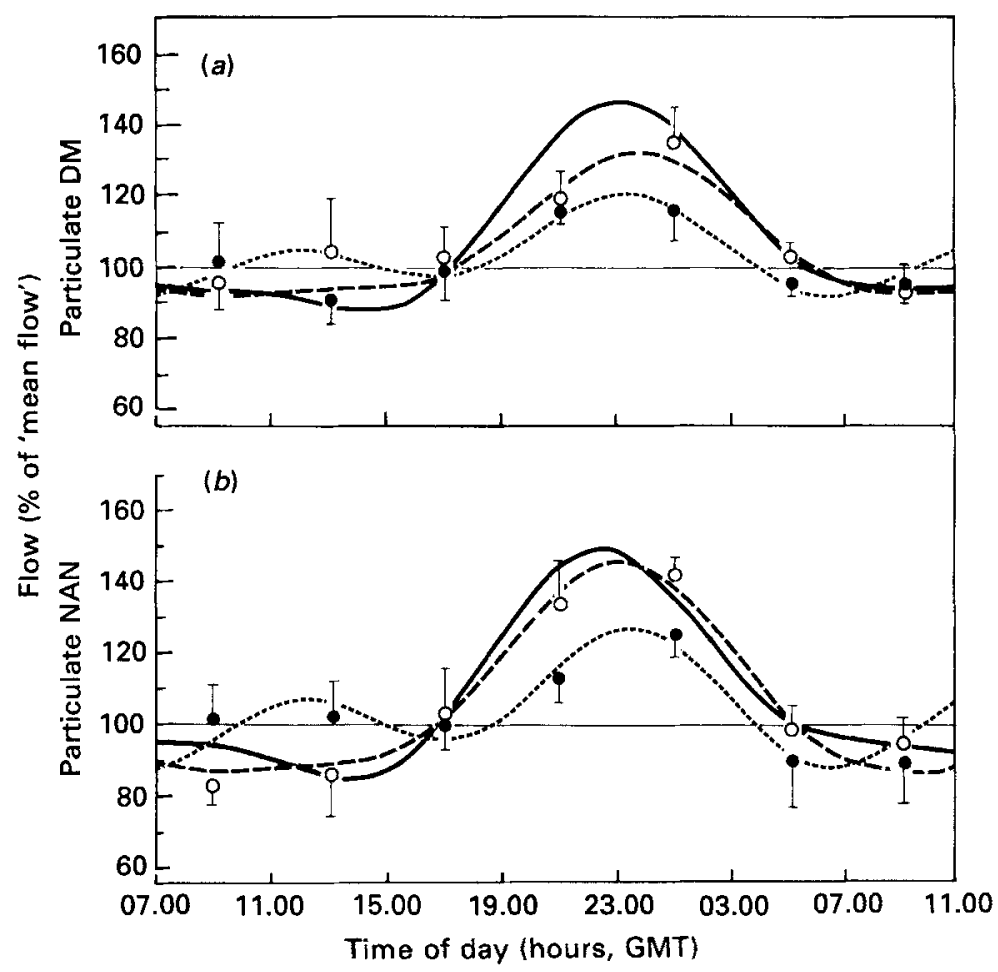

Fig. 3. Circadian variation in the flows of (a) dry matter (DM) and (b) non-ammonia-nitrogen (NAN) in the particulate phase of digesta in ewes grazing perennial ryegrass (Lolium perenne L.) and given either the energy supplement $(600 \mathrm{~g}$ pelleted molassed sugar-beet pulp (MSBP)) $(\mathrm{O}-\mathrm{O}$ ) or protein supplement (600 g MSBP-formaldehyde-treated soya-bean meal $(1: 1, w / w))(\ldots)$ ). Points represent means, with their standard errors represented by vertical bars, across sheep and sampling days. The equations describing the fitted Fourier curves are given in Table 2. Curves for unsupplemented ewes (-) are shown for comparison.

Table 3. Coefficients of the Fourier equations describing the circadian variation in the estimated proportion of the dry matter (DM) and non-ammonia-nitrogen $(N A N)$ flowing in the particulate phase of abomasal digesta in supplemented and unsupplemented ewes grazing perennial rygrass (Lolium perenne $L$.)

(Flow estimated at time $t$ (radians, GMT) as a percentage of daily flow estimated from $24 \mathrm{~h}$ mean marker concentrations, where flow $=a+b \sin (t)+c \cos (t)+d \sin (2 t)+e \cos (2 t))$

\begin{tabular}{|c|c|c|c|c|c|c|c|c|}
\hline \multirow[b]{2}{*}{ Supplement } & \multirow[b]{2}{*}{ Component } & \multicolumn{5}{|c|}{ Regression coefficients } & \multirow{2}{*}{$\begin{array}{l}\text { Residual } \\
\text { SD }\end{array}$} & \multirow{2}{*}{$\begin{array}{c}\text { Statistical } \\
\text { significance }\end{array}$} \\
\hline & & $a$ & $b$ & $c$ & $d$ & $e$ & & \\
\hline None & $\begin{array}{l}\text { DM } \\
\text { NAN }\end{array}$ & $\begin{array}{l}60 \cdot 10 \\
62 \cdot 04\end{array}$ & $\begin{array}{r}0.89 \\
-0.91\end{array}$ & $\begin{array}{l}-2 \cdot 16 \\
-0 \cdot 76\end{array}$ & $\begin{array}{l}-0.45 \\
-1.25\end{array}$ & $\begin{array}{l}-1 \cdot 79 \\
-0.77\end{array}$ & $\begin{array}{l}15 \cdot 100 \\
15 \cdot 059\end{array}$ & $\begin{array}{l}\text { NS } \\
\text { NS }\end{array}$ \\
\hline Energy & $\begin{array}{l}\text { DM } \\
\text { NAN }\end{array}$ & $\begin{array}{l}65 \cdot 21 \\
67 \cdot 31\end{array}$ & $\begin{array}{l}4.49 \\
0.06\end{array}$ & $\begin{array}{l}2.45 \\
8 \cdot 17\end{array}$ & $\begin{array}{l}-3 \cdot 12 \\
-3 \cdot 60\end{array}$ & $\begin{array}{l}-5 \cdot 39 \\
-8 \cdot 30\end{array}$ & $\begin{array}{l}13 \cdot 671 \\
11 \cdot 179\end{array}$ & $\begin{array}{c}\text { NS } \\
P<0.05\end{array}$ \\
\hline Protein & $\begin{array}{l}\text { DM } \\
\text { NAN }\end{array}$ & $\begin{array}{l}63 \cdot 62 \\
61 \cdot 38\end{array}$ & $\begin{array}{l}2 \cdot 81 \\
3 \cdot 50\end{array}$ & $\begin{array}{l}-3 \cdot 78 \\
-6 \cdot 26\end{array}$ & $\begin{array}{r}0 \cdot 38 \\
-1 \cdot 04\end{array}$ & $\begin{array}{l}3 \cdot 23 \\
5 \cdot 84\end{array}$ & $\begin{array}{r}9.531 \\
10.039\end{array}$ & $\begin{array}{c}\text { NS } \\
0.05<P<0.10\end{array}$ \\
\hline
\end{tabular}




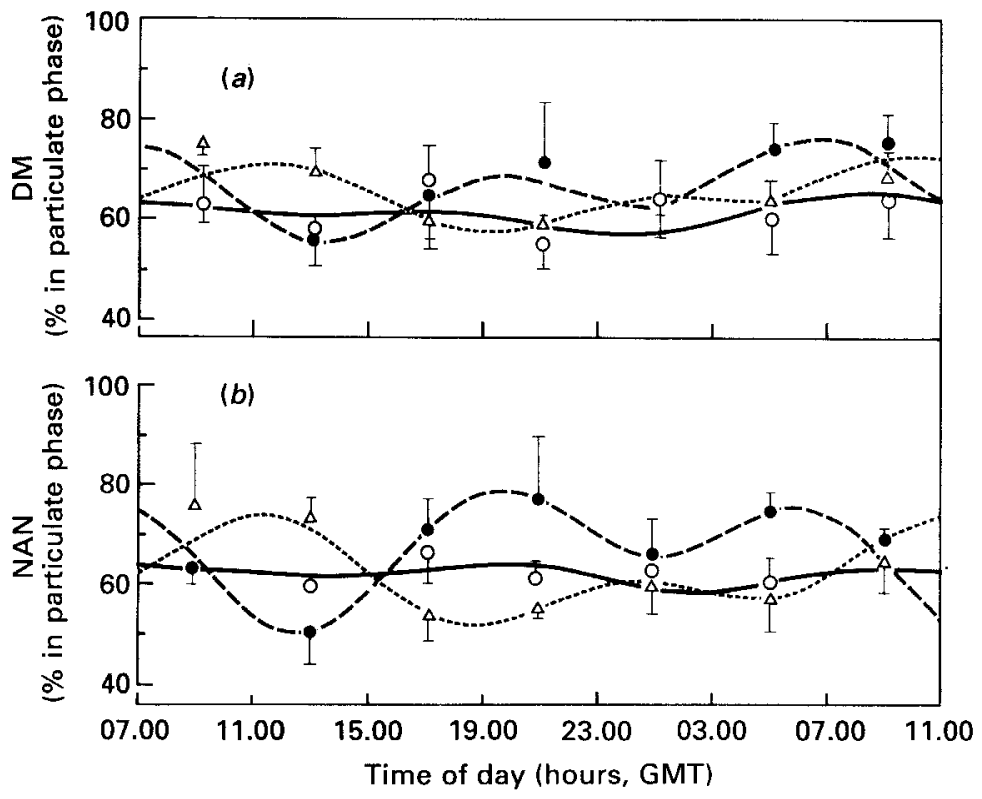

Fig. 4. Circadian variation in the proportion of (a) dry matter (DM) and (b) non-ammonia-nitrogen (NAN) flowing in the particulate phase of digesta in supplemented and unsupplemented ewes grazing perennial ryegrass (Lolium perenne L.). The equations for the fitted Fourier curves are given in Table 3. $(\mathrm{O}-\mathrm{O})$, No supplement; $\left(\mathrm{O}^{-}\right)$, energy supplement $(600 \mathrm{~g}$ pelleted molassed sugar-beet pulp $(\mathrm{MSBP})),(\triangle \ldots \triangle)$, protein supplement $(600 \mathrm{~g}$ MSBP-formaldehyde-treated soya-bean meal $(1: 1, \mathrm{w} /$ w)). Points represent means, with their standard errors represented by vertical bars.

curves fitted to values for ewes given the protein or energy supplements differed from each other $(P<0.005)$, while the difference between these curves and those for unsupplemented animals approached significance $(0.05<P<0 \cdot 10)$. The curve for ewes fed on the protein supplement shows a clear increase in the proportion of NAN flowing in the particulate phase in the period soon after supplementation, followed by a gradual return to values equivalent to unsupplemented animals. In ewes given the energy supplement, the situation is less clear-cut but suggests a decrease in the proportion of NAN flow in the particulate pahse in the period following supplementation.

\section{DISCUSSION}

\section{Circadian variation in digesta flow in unsupplemented animals}

Circadian variation in digesta flow in grazing castrate male sheep has been demonstrated (Corbett \& Pickering, 1983) and shown not to be an artifact of the sampling procedures. We observed similar patterns in grazing ewes in late lactation (Table 1). The residual standard deviations in Table 1 are, in general, about twice those quoted by Corbett \& Pickering (1983), but these authors fitted their curves to values averaged across sheep at each sampling time. The equations in Table 1 were derived using all individual values. Recalculation of our Fourier curves using treatment means resulted in residual standard deviations comparable with those of Corbett \& Pickering (1983). We also suggest that our observed circadian patterns are not marker artifacts, since preliminary examination of our values showed no circadian variation in the ratio of the two digesta flow markers in our 


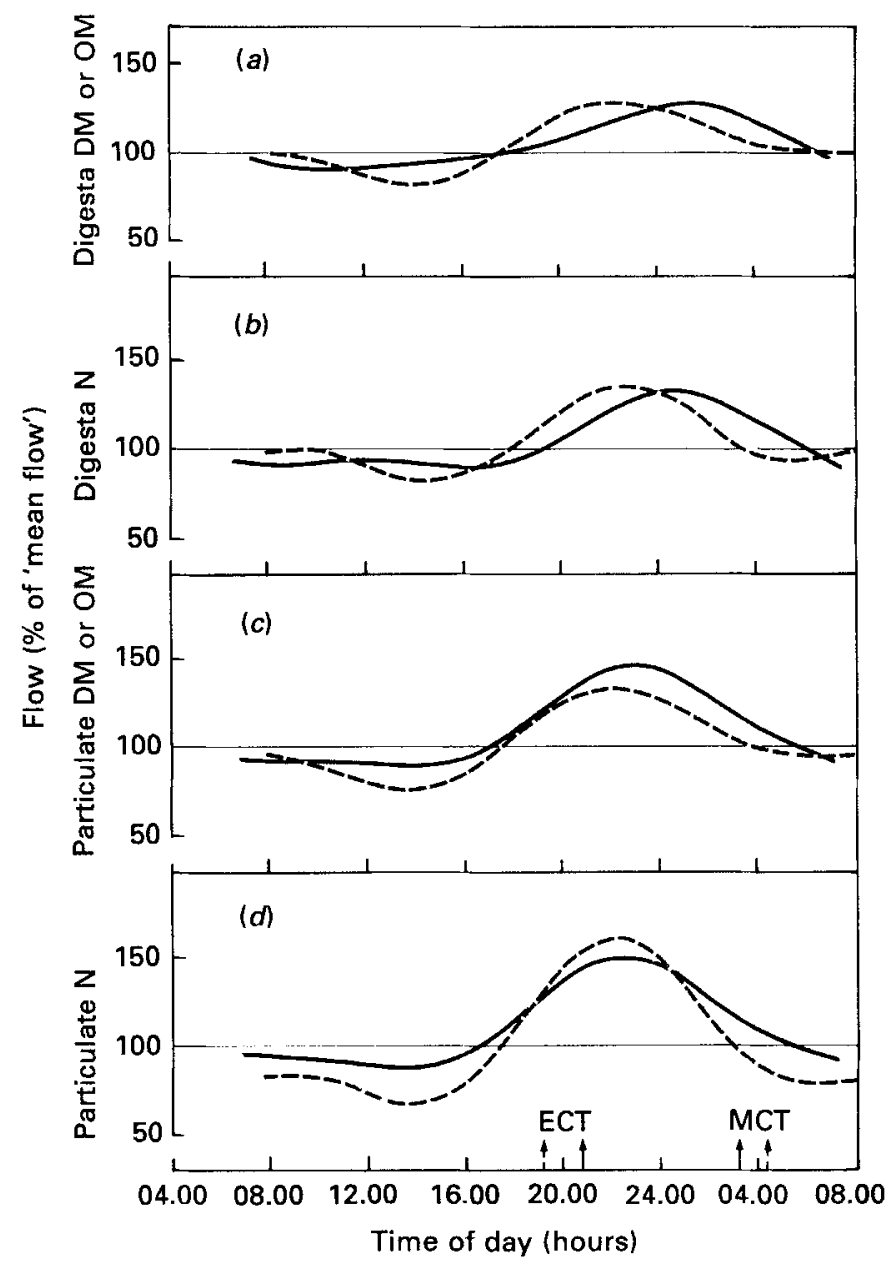

Fig. 5. Comparison of the Fourier curves describing the circadian variation in the flows of $(a)$ dry matter $(D M)$ and $(b)$ total nitrogen in whole digesta and (c) DM and (d) total $\mathrm{N}$ in the particulate phase of digesta in the unsupplemented ewes grazing perennial ryegrass (Lolium perenne L.) in the present study $(-)$, and curves of Corbett \& Pickering (1983) (---) for animals grazing perennial ryegrass in their Expt 10. The curves of Corbett \& Pickering (1983) refer to organic matter (OM) rather than DM. All curves are expressed in relation to the local standard time (present study, GMT; previous study, Australian Eastern Standard Time). $\uparrow \uparrow$, Times of Morning (MCT) and Evening Civil Twilight (ECT) (Edinburgh $55^{\circ} 56^{\prime} \mathrm{N}, 3$ August $03.19,20.52$ hours and Armidale $30^{\circ} 36^{\prime} \mathrm{S}, 6$ December $04.24,19.19$ hours respectively).

samples. Further support for this suggestion comes from the observations of similar circadian variation in digesta flow, based on direct measurement, in housed sheep (Harris \& Phillipson, 1962) and cattle (Wanderley et al. 1985) fed twice daily, a situation which approximates grazing in long daylengths (Lynch \& Hedges, 1979; Corbett \& Pickering, 1983).

Despite the differences in breed, sex, physiological state, pasture environment and daylength, the form of the fitted Fourier curves is remarkably similar to those of Corbett \& Pickering (1983), as can be seen in Fig. 5 for digesta components and particulate-phase components. The curves from Corbett \& Pickering (1983) have been recalculated from the 


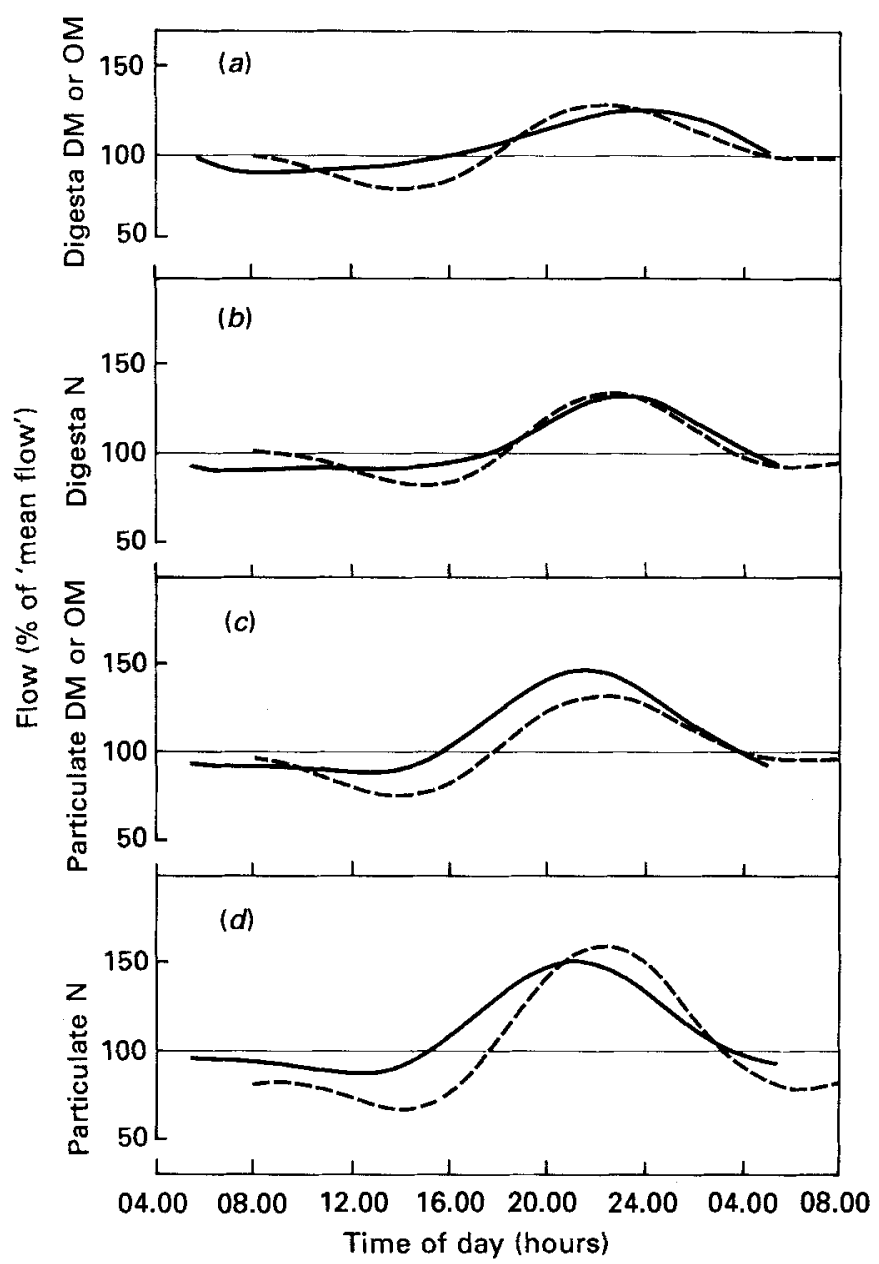

Fig. 6. Re-expression of the Fourier curves shown in Fig. 5 after adjustment to the common time of Evening Civil Twilight at Armidale $\left(30^{\circ} 36^{\prime} \mathrm{S}\right)$ on 6 December. (-), Present study; (---), Corbett \& Pickering (1983). (a) Dry matter (DM) and (b) total nitrogen in whole digesta and (c) DM and $(d)$ total $\mathrm{N}$ in the particulate phase of digesta in unsupplemented sheep grazing perennial ryegrass (Lolium perenne L.) in the present study, and for animals grazing perennial ryegrass in Expt 10 of Corbett \& Pickering (1983). The curves of Corbett \& Pickering (1983) refer to organic matter (OM) rather than DM.

original values of their Expt 10, in which animals grazed a pasture of predominantly perennial ryegrass similar to that grazed by our animals.

In both studies, digesta DM or OM flows were at their lowest between dawn and late afternoon. Peak flow, which in both studies was some $30 \%$ greater than the flow calculated from mean marker concentrations, occurred between 22.00 and 02.00 hours. The results presented by Langlands (1965) indicated a rise in the $N$ content of the diet selected by grazing sheep as the day progressed. This was not measured directly in our study, but there were no temporal trends in the $\mathrm{N}$ or NAN content of abomasal digesta in unsupplemented ewes so that the pattern of flow of digesta NAN was essentially the same as digesta DM (Fig. 5(b)) and again, similar to that reported by Corbett \& Pickering (1983). The amplitude of the circadian variation in the particulate phase was greater in both 
Table 4. Influence of method of expression of time-base on residual mean squares of the fitted Fourier curves

\begin{tabular}{|c|c|c|c|c|c|}
\hline \multirow[b]{2}{*}{ Phase } & \multirow[b]{2}{*}{ Component } & \multicolumn{4}{|c|}{ Residual mean square (\% change) } \\
\hline & & Standard time $\dagger$ & Common ECT $\dagger$ & Comm & $\mathrm{n} \mathrm{MCT} \dagger$ \\
\hline Digesta & $\begin{array}{l}\mathrm{DM} \text { or } \mathrm{OM} \ddagger \\
\text { Total nitrogen }\end{array}$ & $\begin{array}{l}73 \cdot 46 \\
83 \cdot 12\end{array}$ & $\begin{array}{cc}67 \cdot 81 & (-7 \cdot 7) \\
52 \cdot 32 & (-37 \cdot 1)\end{array}$ & $\begin{array}{r}86 \cdot 74 \\
123 \cdot 24\end{array}$ & $\begin{array}{l}(+18 \cdot 1) \\
(+48 \cdot 3)\end{array}$ \\
\hline Particulate & $\begin{array}{l}\text { DM or OM } \\
\text { Total nitrogen }\end{array}$ & $\begin{array}{r}80 \cdot 65 \\
103 \cdot 84\end{array}$ & $\begin{aligned} 99 \cdot 08 & (+22 \cdot 9) \\
136.01 & (+31 \cdot 0)\end{aligned}$ & $\begin{array}{r}99.08 \\
145.46\end{array}$ & $\begin{array}{l}(+22 \cdot 9) \\
(+40 \cdot 1)\end{array}$ \\
\hline
\end{tabular}

DM, dry matter; OM, organic matter.

Curves fitted to the appropriate combined values of the present study and those of Expt 10 of Corbett \& Pickering (1983).

$\dagger$ Standard time, GMT (present study) or Australian Eastern Standard time (Corbett \& Pickering, 1983); Common ECT, corrected to common Evening Civil Twilight at Armidale (30 36 $\mathrm{S}$ ) on 6 December (19.19 hours); Common MCT, corrected to common Morning Civil Twilight at Armidale (30 $36^{\prime} S$ ) on 6 December (04.24 hours).

¥DM in present values; OM in values from Corbett \& Pickering (1983).

studies, though the timing of peaks and troughs follows that found for digesta and was not statistically different.

Lynch \& Hedges (1979) noted that grazing behaviour could be related to the time of Morning Civil Twilight (MCT) and Evening Civil Twilight (ECT). This led Corbett \& Pickering (1983) to compare patterns of digesta flow, measured at different times of the year, by correcting the time-bases to a common MCT or ECT. Correction to a common MCT introduced significant variation between fitted curves, whereas those corrected to a common ECT were not significantly different.

In Fig. 6 the Fourier curves in Fig. 5 are re-expressed in relation to a common ECT (that for 6 December; Armidale $33^{\circ} 36^{\prime} \mathrm{S}$ ). For digesta flows, this results in even closer correspondence between the studies than was obvious in Fig. 5. The effect with flows in the particulate phase is less clear-cut. A more quantitative approach was attempted by comparing the separate curves (our Fourier curves, fitted to values averaged across sheep within sampling time, and curves using corresponding values from Corbett \& Pickering (1983)) with a common curve through the combined values. This exercise was conducted with time expressed either as local standard time, or in relation to the common MCT or ECT prevailing at Armidale, Australia, as described previously. With Fourier curves related to standard time, our curves did not differ significantly from those of the earlier study, i.e. the fitting of a common curve did not significantly increase the residual mean square after regression. This confirms the impression created by Fig. 5 that the responses in the two studies were similar. In Table 4, we present the residual mean squares for the common fitted curves for each time-base. With whole digesta, adjustment of the values to a common ECT effected a substantial reduction in the residual mean square, particularly for $\mathbf{N}$ flow. This in turn confirms the impression gained from Fig. 6. By constrast, adjustment to a common MCT markedly increased the residual mean square. These trends are very similar to those noted by Corbett \& Pickering (1983) and lend strong support to the idea that the observed circadian patterns are real phenomena.

When similar adjustments were made for the particulate phase, marked increases in residual mean squares were noted for either Civial Twilight correction. However these changes in residual mean squares, while large, were not statistically significant.

Circadian patterns in the pool size of, and flow through, digesta compartments are 
presumably related to the patterns of grazing, drinking and rumination, and the effect that these have on rumen fill and outflow. Corbett \& Pickering (1983) observed that the circadian patterns of rumen fill and abomasal digesta flow were similar, and presented evidence that these patterns were more influenced by rumination pattern than by the timing of grazing. However, recent direct measurements of the circadian variation in rumen fill (Thomson et al. 1985) suggest that the rate of intake may also be a contributor.

Hence, while the patterns of abomasal digesta flow in Figs. 5 and 6 are consistent with a range of observations of grazing and rumination activity, the underlying mechanisms are a matter of speculation until simultaneous measurements are made of these activities and digesta pools and flows.

Influence of supplementary feeding and supplement type on circadian variation The feeding of supplements influenced the absolute flows of DM and NAN, both in the present study and earlier in lactation (Dove et al. 1985). Apart from this effect, the supplements could be expected to perturb the 'normal' circadian pattern of digesta flow either directly, or indirectly through an effect on the pattern of grazing or drinking activity or pattern of rumination. The findings presented in Table 2 and Fig. 2 indicate that, in general, the circadian variation in flow of whole digesta was similar to that found in unsupplemented animals, suggesting that this further departure from steady-state conditions had not prevented a valid estimation of digesta flow. Though the curves for digesta DM flow in supplemented animals were not significantly different from those for unsupplemented animals, their peak did appear to be reached earlier and, in the case of the energy supplement, was greater in amplitude and preceded by a subsidiary peak in the early afternoon. These differences were even more marked in digesta NAN flow, in which case the curves for supplemented animals were significantly different from those for unsupplemented animals. This has repercussions for sampling schedules (see p. 667). Curves describing the flow in the particulate phase in supplemented animals were more similar to those for unsupplemented animals than the equivalent whole-digesta curves, though a marked subsidiary peak was apparent in NAN flow in the particulate phase of digesta for ewes given the protein supplement.

The mechanisms by which these supplements exert any influence on circadian patterns of digesta flow await elucidation. However, the results in Fig. 4 suggest that, in the period soon after supplementation (09.00-14.00 hours), there was a decreased flow of material in the particulate phase of digesta or, by inference, an increased flow in the liquid phase. This would be consistent with the known high level of soluble carbohydrates in molassed-sugarbeet pulp (Ministry of Agriculture, Fisheries and Food, 1975) and its rapid digestion rate in the rumen.

By contrast, the protein supplement caused a significant increase in the flow of DM and NAN in the particulate phase, in the period soon after supplementation. The results of our nylon-bag assay showed that the formaldehyde treatment of the soya-bean meal had greatly reduced its rate of rumen digestion, without influencing its overall digestibility. Faichney $(1975 b)$ demonstrated that, relative to an untreated diet, formaldehyde treatment of the same diet reduced the mean retention time of both soluble and particulate matter in the rumen, and suggested that this was due to increased propulsive activity in the rumen. A similar mechanism operating in the present study would be expected to result in increased flow in the particulate phase in the period following the feeding of the protein supplement. Certainly, granules indentifiable as crushed soya-bean meal were frequently seen in digesta samples collected in the afternoon.

In interpreting the effect of supplements on digesta flow, possible indirect effects must also be considered. Apart from unknown effects on water intake, supplements might 
Table 5. Estimated flows of dry matter $(D M)$ and non-ammonia-nitrogen $(N A N)$ in whole digesta and particulate phase as a consequence of intermittent sampling

(Values are calculated using the expressions in Tables 1 and 2 and are expressed as percentages of the flow calculated from daily mean marker concentrations. The assumed sampling schedule was $09.00,13.00$, 17.00 and 09.00 hours)

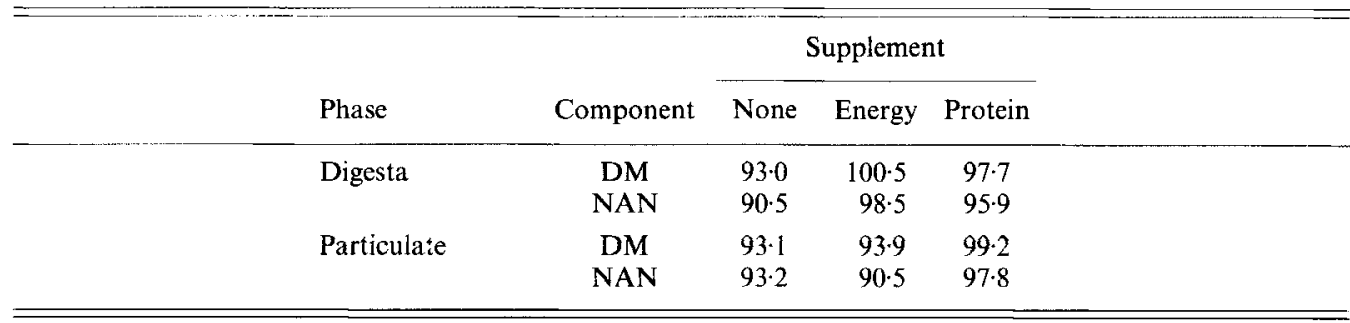

increase or decrease the time-period spent grazing (Tribe, 1950; Holder, 1962). We did not measure grazing time, but in lactating Border Leicester $\times$ Merino ewes, consumption of $500 \mathrm{~g}$ sunflower meal/d did not reduce grazing time compared with unsupplemented controls, though, as in many studies, it reduced pasture intake (Dove et al. $1984 b ; \mathrm{H}$. Dove, M. Freer and A. R. Egan, unpublished results). The relative effects of the direct and indirect influences of supplements on digesta flow cannot be defined from our study. This, coupled with the large between-animal variability in supplement intake in group-fed animals (Dove, 1984; Dove et al. 1984b), implies that caution should be exercised in extrapolating our measured responses to supplementation in other situations.

\section{Influence of circadian variation on the accuracy of digesta sampling}

The existence of a circadian pattern of digesta flow means that it would be possible, through an injudicious choice of sampling times, to obtain a digesta sample in which the concentrations of the digesta markers did not accurately reflect the true daily flow of digesta. In our studies in the same animals earlier in lactation (Dove et al. 1985), samples of abomasal digesta were collected at $09.00,13.00,17.00$ and 09.00 hours the following day. From the equations given in Tables 1 and 2, it is possible to calculate the consequences of employing that same sampling schedule in the present study. These results, expressed as percentages of the flow calculated from mean marker concentrations, are given in Table 5.

In unsupplemented animals, the use of the above sampling schedule would have resulted in underestimates of 7-10\% in the flow of DM or NAN in whole digesta or the particulate phase. In animals given the energy supplement no underestimate of digesta flows would have occurred, though flows in the particulate phase would again have been underestimated by $7-10 \%$. In ewes given the protein supplement only small underestimates would have occurred.

These considerations suggest that steps should be taken to ensure that a chosen sampling schedule does truly accommodate the pattern of flow, though it is encouraging that the present results suggest that a failure to do so might not result in large errors. Corbett \& Pickering (1983) suggested that the results from an infrequent sampling schedule could be corrected using Fourier analysis, but this requires that the circadian variation has already been measured and described. An alternative, but probably no less laborious procedure is that used by Faichney (1980) in which samples are taken over several days in such a way as to sample a large number of putative periods within the $24 \mathrm{~h}$ total. 
The authors gratefully acknowledge the technical assistance of Miss Vicki Farr and the assistance of $\mathrm{Mr}$ E. Skedd, Mr J. McKenzie and their laboratory staff. They also thank $\mathrm{Mr}$ W. Souter for providing the oesophageally fistulated animals. Dr J. L. Corbett kindly made available his original values and statistical analyses, while further statistical advice was given by Mr W. J. Müller of the Division of Mathematics and Statistics, CSIRO. The work was conducted while the senior author was a Visiting Scientist at the then Hill Farming Research Organization, Penicuik, Midlothian, with the financial assistance of the Stapledon Memorial Trust and the Australia-Britain Society.

\section{REFERENCES}

Alexander, R. H. \& McGowan, M. (1966). Journal of the British Grassland Society 21, 140-147.

Binnerts, W. T., Van't Klooster, A. T. \& Frens, A. M. (1968). Veterinary Record 82, 470.

Corbett, J. L., Lynch, J. J., Nicol, G. R. \& Beeston, J. W. U. (1976). Laboratory Practice 25, 458462.

Corbett, J. L. \& Pickering, F. S. (1983). Australian Journal of Agricultural Research 34, 193-210.

Dove, H. (1984). Australian Journal of Experimental Agriculture and Animal Husbandry 24, 484-493.

Dove, H., Freer, M., Axelsen, A. \& Downes, R. W. (1984a). Proceedings of the Australian Society of Animal Production 15, 329-332.

Dove, H., Freer, M., Egan, A. R. \& Doyle, P. T. (1984b). Proceedings of the Nutrition Society of Australia 9 , 166.

Dove, H., Milne, J. A., Lamb, C. S., McCormack, H. A., \& Spence, A. M. (1985). Proceedings of the Nutrition Society 44, 63A.

Evans, C. C., MacRae, J. C. \& Wilson, S. (1977). Journal of Agricultural Science, Cambridge 89, $17-22$.

Faichney, G. J. (1975a). In Digestion and Metabolism in the Ruminant, pp. 277-291 [I. W. McDonald and A. C. I. Warner, editors]. Armidale: University of New England.

Faichney, G. J. (1975 b). Australian Journal of Agricultural Research 26, 319-327.

Faichney, G. J. (1980). Journal of Agricultural Science, Cambridge 94, 313-318.

Freer, M. \& Dove, H. (1984). Animal Food Science and Technology 11, 87-101.

GENSTAT (1977) GENSTAT, A General Statistical Program. Oxford: Numerical Algorithms Group.

Harris, L. E. \& Phillipson, A. T. (1962). Animal Production, 4, 97-116.

Holder, J. M. (1962). Proceedings of the Australian Society of Animal Production 4, 154-159.

Langlands, J. P. (1965). Nature 207, 666667.

Lynch, J. J. \& Hedges, D. A. (1979). Applied Animal Ethology 5, 321-331.

Milne, J. A., Maxwell, T. J. \& Souter, W. (1981). Animal Production 32, 185-195.

Ministry of Agriculture, Fisheries and Food (1975). Energy Allowances and Feeding Systems for Ruminants. Technical Bulletin, no. 33. London: H.M. Stationery Office.

Rowell, J. G. \& Walters, D. E. (1976). Journal of Agricultural Science, Cambridge 87, 423 432.

Tan, T. N., Weston, R. H. \& Hogan, J. P. (1971). International Journal of Applied Radiation and Isotopes 22, $301-308$.

Thomson, B. C., Cruickshank, G. J., Poppi, D. P. \& Sykes, A. R. (1985). Proceedings of the New Zealand Society of Animal Production 45, 117-120.

Tilley, J. M. A. \& Terry, R. A. (1963). Journal of the British Grassland Society 18, 104-111.

Tribe, D. E. (1950). Nature 166, 74.

Wanderley, R. C., Theurer, C. B., Rahnema, S. \& Noon, T. H. (1985). Journal of Animal Science 61, 1550-1558. 